\title{
Workplace Bullying Among Higher Education Faculty: A Review of the Theoretical and Empirical Literature
}

\author{
Kathy Lemon \\ San Jose State University \\ Kendra Barnes \\ San Jose State University
}

This review of the theoretical and empirical literature on workplace bullying and mobbing in higher education provides a synthesis of knowledge on this topic. The theoretical origins of the concepts are identified and current empirical evidence on prevalence, characteristics of the target, duration, causes, effects and responses to abusive conduct among faculty are summarized. Evidence suggests that higher education workplaces are particularly vulnerable to workplace abuse due to their institutional structures and organizational cultures. Gaps in our knowledge base on this topic are identified and areas of future research are described.

Keywords: workplace bullying, workplace mobbing, higher education, harassment, faculty, abusive conduct, retaliation

\section{INTRODUCTION}

Despite the widespread perception that university workplaces uphold standards of ethical dialogue, professional debate, and collegial problem-solving, research suggests that workplace bullying and mobbing in higher education are pervasive (Hollis, 2015; Keashly \& Neuman, 2010). Entering the higher education field as a faculty member puts one at risk for becoming a target of ongoing abusive conduct, including hostile communication, social exclusion, punitive work assignments, and other harmful behaviors (Keashly \& Neuman, 2013; Twale, 2018). In the United States, research on workplace bullying in higher education settings is stymied in part by the absence of a national workplace bullying policy (Hollis, 2017a; Stone, 2013; Workplace Bullying Institute [WBI], 2021). This lack of attention to preventative policies on workplace abusive conduct is troubling given the well-established evidence indicating that workplace bullying and mobbing are devastating to the health, well-being and job satisfaction of targeted individuals, as well as the success of the organization (McKay et al., 2008; Meriläinen, Köiv et al., 2019). This literature review presents a synthesis of research on the theoretical origins of the concepts of workplace bullying and mobbing, and then focuses specifically on how these concepts manifest among faculty in higher education institutions, including the empirical evidence on prevalence, characteristics of the target, duration, causes, effects and responses to abusive conduct. Gaps in the knowledge base are identified and implications for research and policy are suggested. 


\section{THEORETICAL ORIGINS}

The origins of scholarly work on abusive conduct in the work environment can be traced to the psychiatrist and anthropologist Carol Brodsky who defined it as "harassment" which involved "repeated and persistent attempts by one person to torment, wear down, frustrate or get a reaction from another" (Brodsky, 1976, p. 2). The concept of mobbing first appeared in the work of ethologist Konrad Lorenz (1966) who described mobbing behaviors in animals and birds, which he believed were related to primal survival instincts. Physician Peter Heinemann (1972) applied Lorenz's conceptualization of mobbing to group aggressive behaviors in children. Nearly two decades later, psychologist Heinz Leymann (1990) extended Heinemann's concepts to the workplace when he observed groups of employees directing aggression toward one targeted member of the organization. He defined workplace mobbing as, "psychical terror or mobbing in working life means hostile and unethical communication which is directed in a systematic way by one or a number of persons mainly toward one individual" (Leymann, 1990, p. 120). This abusive conduct extends beyond occasional conflicts and is considered to be motivated by aggression stemming from innate fight-or-flight responses to a threatening, competitive and stressful environment (Klein \& Lester, 2013). These aggressive acts cause significant psychological and organizational distress (Matthiessen \& Einarsen, 2004; Meriläinen, Köiv et al., 2019).

Further refinement to the definition of workplace bullying comes from the Bergen Bullying Research Group (2020) in Norway whose researchers developed the Negative Acts Questionnaire, which asks respondents to report the frequency of specific workplace abusive conduct over the previous 6 months, from daily to never. These dehumanizing experiences are measured on an individual level, such as: insults, ridicule, being ignored, being shouted at, or spreading gossip; and on an organizational level, such as being assigned an excessive workload, or replacing important areas of responsibility with more menial tasks, being given unreasonable deadlines, or persistent criticism of one's work (Einarsen et al., 1994; Einarsen et al., 2009). Whether personal, organizational, or both, the behaviors become abusive in nature when they are consistently repeated and the process becomes increasingly excessive over time (Einarsen et al., 2003).

In the United States, the Workplace Bullying Institute (WBI) (Namie, 2021b) has coordinated five nationally representative surveys on the prevalence and effects of workplace bullying for both targets and witnesses. The WBI measures workplace bullying by using the definition of workplace abusive conduct that is contained in the Healthy Workplace Bill, a national policy that has yet to be adopted in the U.S. This definition asks respondents about their personal experiences with repeated mistreatment in the workplace, including: "abusive conduct that is threatening, intimidating, humiliating, work sabotage or verbal abuse" (Namie, 2021b, p. 3). This definition incorporates the key components of abusive conduct in the workplace: it is repetitive and includes personal and organizational mistreatment.

The terms bullying and mobbing are used interchangeably in some research literature (Einarsen et al., 2011) and are treated as separate concepts in other studies (Duffy \& Sperry, 2012). This review of the research includes studies that use both terms or either term. Research that is specific to faculty in higher education settings is limited and the inclusion of both terms allows for the most robust overview of the state of knowledge on this topic. In addition, the evidence suggests that regardless of whether the term bullying or mobbing is used, the target suffers in equally destructive ways, suggesting that methodological or theoretical distinctions between the terms may not consistently translate to meaningful differences in reality (Duffy \& Sperry, 2014; Twale, 2018).

\section{PREVALENCE}

Researchers use two mechanisms to measure workplace bullying and mobbing: The labeling approach asks the respondent to self-identify as a target of workplace bullying and the checklist approach includes a checklist of bullying and mobbing behaviors which is summed into a continuous score that is used to create a dichotomous measure with a researcher-defined cut-off score to determine target status (Keashly \& Neuman, 2008). Prevalence rates of bullying in higher education vary based on these differences in measurement methods. In addition, the time frame in which the behaviors are being measured also affects 
prevalence rates. Some measurements refer to incidence within the previous 6 months, while other measurements do not use a time period or use lengthier time frames. Variations in other study parameters, such as sample characteristics (tenure track faculty, lecturers, staff); study location (U.S. and other international settings) and type of educational institution (public vs. private universities and four-year vs. two-year) also contribute to differences in prevalence rates across studies. Despite these differences, crosssectional survey research from faculty in higher education settings in North America and internationally, documents the extent of workplace bullying and mobbing in universities and colleges.

Studies from countries outside the U.S. suggest that approximately one out of five faculty in higher education are targets of workplace bullying. For example, Meriläinen, Käyhkö et al. (2019) used the labeling approach within a 6-month time period with two faculty samples, one from Estonia with 864 respondents (prevalence $=27 \%$ ) and one from Finland with 327 respondents (prevalence $=18 \%$ ). Similarly, Erdemir et al. (2020) conducted a survey of 547 faculty members in Turkey (full professors, associate professors, assistant professors, research assistants, instructors, and specialists) and reported that $21 \%$ of respondents were targets of workplace mobbing (using the checklist method with a researcher-defined cutoff). Yildirim et al. (2007) surveyed 210 faculty members (professors, associate professors, assistant professors, instructors and research assistants) employed at 11 university nursing schools in Turkey and found that $91 \%$ reported experiencing at least one mobbing behavior with $17 \%$ being determined to be a target of bullying (using the checklist approach with a researcher defined cut-off). Lastly, Anjum and Muazzam (2018) used the checklist method with a researcher defined-cut-off score and reported a $60 \%$ prevalence rate from their survey of 400 faculty in Pakistan.

Survey research in North America points to somewhat higher prevalence rates than in international studies. For example, McKay et al. (2008) surveyed 100 respondents at a Canadian university including tenure-track faculty, non-tenure track faculty and librarians. Using the labeling measurement method, 52\% of respondents believed they had been bullied over the previous five years and an additional $10 \%$ were unsure. In addition, Cassidy et al. (2014) surveyed 121 faculty members at a Canadian university and found that $17 \%$ of the sample had experienced cyberbullying (using the labeling method).

In the U.S., Hollis (2015) surveyed 401 participants (including both administrators and faculty) across 175 four-year universities in the Eastern U.S. and found that $62 \%$ of respondents identified themselves as a target or reported they had witnessed workplace bullying. Similarly, Hollis (2016a) investigated the extent of workplace bullying among 201 faculty at 142 community colleges and found a $64 \%$ prevalence rate (using the labeling method). Using a separate sample of 557 faculty from across 317 universities and colleges Hollis (2017b) found that $34 \%$ of faculty self-identified as a target of vicarious bullying, which was defined as being perpetrated by secondary bullies, who are associated with a primary bully and carry out abusive conduct on their behalf. Hollis (2019a) further examined vicarious bullying in a sample of 729 faculty and administrators across a variety of U.S universities and colleges and found that $42 \%$ selfidentified as targets of vicarious bullying.

Studies surveying single universities in the U.S. suggest similarly high prevalence rates of workplace bullying and mobbing at this smaller unit of analysis. For example, Mourssi-Alfash (2014) surveyed 786 faculty and staff at a Midwestern university in the U.S. and found that $82.4 \%$ reported experiencing at least one bullying behavior in the previous six months; $38.9 \%$ were rated as being bullied based on a researcherdefined cut-off survey score and $37.9 \%$ characterized themselves as a target of workplace bullying. Similarly, Taylor (2012) surveyed 1,060 full-time faculty members (tenured, tenure-track and non-tenure track) at the University of Minnesota Twin Cities and found that $12.1 \%$ of faculty labeled themselves as a target of workplace bullying, $68.3 \%$ had experienced one or more bullying behaviors on a weekly basis, and $22.3 \%$ indicated that they had witnessed another faculty member being bullied. Keashly and Neuman (2008) found that among 1,185 faculty at Minnesota State University Mankato 68\% reported experiencing some form of workplace bullying and using the score cut-off method, $23 \%$ were classified as targets of workplace bullying. In addition, $32 \%$ self-identified as targets and $41 \%$ reported being a witness. Tran (2019) conducted a survey with 97 faculty members (adjunct and full-time) at a small community college in the Southern United States and reported a 34\% prevalence rate (using the self-identification approach). 


\section{CHARACTERISTICS OF THE TARGET}

Anyone is susceptible to becoming the target of workplace bullying and mobbing; however, the risk of abuse increases when the characteristics of an individual differ from the majority in a specific work setting (Duffy \& Sperry, 2014; Westhues, 2006). Any characteristic that varies from the prevailing norms, including but not limited to: gender, age, race/ethnicity, sexual orientation, parental status, marital status, foreign-born status, religious preference, political preference, or disability status can make a faculty member vulnerable to workplace abusive conduct (Duffy \& Sperry, 2014). Overall, prevalence rates tend to be higher for female faculty in the U.S. and internationally. Both Taylor (2012) and Mourssi-Alfash's (2014) surveys of faculty found women to be targets more often than men. Similarly, Anjum and Muazzam (2018) found that women comprised a higher proportion of targets (35\%) compared to men (25\%). Cassidy et al. (2014) reported a prevalence rate of $22 \%$ for women and $6 \%$ for male faculty. And Erdemir et al. (2020) used multivariate analyses and found that female faculty were more likely to experience mobbing behaviors than male faculty. Finally, Hollis (2019a) found women faculty (45\%) to report a higher proportion of being the target of vicarious bullying compared to men $(36 \%)$.

In the U.S. there is evidence that faculty of color experience higher prevalence rates for workplace bullying and mobbing than white faculty. In Hollis' (2016a) survey of faculty in the community college system, $73 \%$ of employees of color were affected by workplace bullying and $52 \%$ had experienced or witnessed vicarious bullying while employed at a community college. For comparison, the rate of bullying and vicarious bullying for the population at large was $64 \%$ and $29 \%$ respectively (Hollis, 2016a). In supplemental analysis of this sample, Hollis and Robinson (2016) reported that $56 \%$ of people of color were targets of cyber bullying, in comparison to $41 \%$ of white individuals. Additional studies (Hollis, 2017b, 2019b; Hollis \& Robinson, 2016) exploring experiences of black professionals working in a university setting revealed that both black women and black men were more likely to be a target of bullying when compared to the overall sample. Specifically, $86.2 \%$ of black women and $75 \%$ of black men faced workplace bullying while employed in academia, which was $24 \%$ and $30 \%$ greater than the overall sample respectively (Hollis, 2016, 2019b; Hollis \& Robinson, 2016).

Although most survey research of faculty bullying experiences does not include a question on sexual orientation, two studies were identified that included this variable in bivariate analyses. Taylor (2012) found that Lesbian/Gay/Bisexual/Transgender faculty were more likely to self-identify as a target of workplace bullying than heterosexual faculty. Similarly, Hollis (2018) found that $100 \%$ of black Lesbian faculty reported being a target of workplace bullying.

Some research has focused on professional and personality characteristics of the target that may provoke envy or other negative emotions in individuals with low levels of emotional maturity. For example, characteristics such as integrity, loyalty, superior competence, cooperativeness, creativity, positivity toward work and a willingness to engage in new ideas are characteristics that are associated with being a target of workplace bullying and mobbing (Davenport et al., 1999; Westhues; 2005). Reasons for such dynamics may be related to sociological research suggesting that work groups respond to high-achieving and lowachieving members in characteristic ways (Goode, 1967; Hermanowicz, 2013). Goode (1967) suggested that once a less-competent individual becomes a member of a work group, they are more likely to be protected than fired, because a termination would draw negative attention to the group. Hermanowicz (2013) extended these ideas to consider what happens when the less-adept comprise the majority of the group and are confronted with a high-achieving member. Applying this question to higher education settings, Hermanowicz (2013) suggests that, rather than protecting the highly competent, a mediocre group will engage in marginalization processes that relegate the individual to an insignificant and powerless position. Tenure often prevents outright termination of the targeted individual and so abusive conduct in the form of bullying and mobbing are used as covert tactics to expel a highly-competent member from a mediocre group (Hermanowicz, 2013). In this context, having tenure and being highly competent can actually increase the likelihood of abusive conduct being used as a strategy for removal from the work group. 


\section{TENURE AND THE DURATION OF THE BULLYING EXPERIENCE}

A distinctive feature of workplace bullying and mobbing among faculty in higher education settings is its lengthy duration, often lasting for multiple years (Hollis, 2015; Keashly \& Neuman, 2008). The uniqueness of tenure creates situations in which faculty often must interact with one another in long-term relationships. As a result, if abusive conduct develops, it may continue for long periods of time (BerrymanFink, 1998; Twale, 2018). Due to the protections of tenure, both termination and resignation in higher education workplaces is low (Taylor, 2013; Westhues, 1998). As a result of this job security, combined with the highly specialized nature of knowledge and training that faculty members must possess in order to enter the higher education field, many may be unable or reluctant to leave an abusive work environment. For an academic, the process of changing jobs or leaving academia altogether may include accepting a lower salary and working below one's competence level, as well as the prospect of beginning a new career trajectory altogether. Simultaneously, the difficulties in employment termination create situations in which bullying may be used as a mechanism to push someone out of the organization (Keashly \& Neuman, 2013; Taylor, 2013; Westhues, 2005).

Survey research provides evidence for the lengthy duration of workplace bullying in higher education and the potential role of tenure in promoting abusive conduct. For example, Taylor (2012) found that faculty who were tenured had higher workplace bullying scale scores than tenure-track faculty. In Keashly and Neuman's (2008) survey, 49\% of targeted faculty had been bullied for three or more years and 34\% reported witnessing abusive conduct for three or more years. Similarly, McKay et al. (2008) reported that among faculty who self-identified as a target of workplace bullying, $21 \%$ said the bullying had been occurring for more than five years and $16 \%$ were currently experiencing abusive conduct. Lastly, Hollis (2015) found targets of workplace bullying experienced the bullying for more than three years and $26 \%$ experienced the bullying for two to three years.

\section{CAUSES}

The causes of workplace bullying and mobbing in higher education settings are multifaceted and involve a combination of individual-level variables and organizational level variables that interact in multiple and bidirectional ways to create and sustain abusive conduct. These antecedents include: attributes of the bully; institutional structures; and organizational culture (Bodensteiner, 2017; Buitenhuis, 2016; Burris, 2012; Lester 2009; Persky, 2018; Wilkin, 2010).

\section{Attributes of the Bully}

An understanding of the typical characteristics of workplace bullies in higher education is hindered by a lack of knowledge surrounding the intentions of perpetrators (Einarsen et al., 2016). However, it is possible to draw on research with targeted faculty to illustrate the perceived attributes of perpetrators of workplace bullying and mobbing in higher education (Lewis, 2004; Persky, 2018). Scholars note these characteristics share similarities with the diagnostic indicators of Narcissistic Personality Disorder (Piotrowski \& King, 2016; Ross et al., 2019). Such indicators include: the need to obtain admiration in order to self-regulate emotions and self-esteem; seeing oneself as exceptional and entitled to special treatment; impairments in empathy; and interpersonal relationships that are largely superficial and used for personal gain (American Psychiatric Association, 2013). These attributes are associated with an inflated sense of self that easily becomes threatened in challenging and competitive environments.

Given the highly competitive nature of academia, and its narrow focus on individual achievements, it is not surprising that targets report bullying behaviors indicative of pathological personality traits. Descriptions of workplace bullies in higher education are replete with these types of attributes. Wilkin (2010) reports that bullies are described as "charismatic," "seductive," "a pit bull," "vindictive," "unprofessional," "paranoid," "manipulative," and "narcissistic." Targets in Burris' (2012) study described bullies as sociopathic, manipulative, and intimidating. Bodensteiner (2017) reports that targets perceived the intentions of bullies as self-serving so that they could improve their rank or status. 


\section{Higher Education Institutional Structures and the Abuse of Power}

The structural characteristics of higher education institutions make university settings susceptible to abuses of power that produce ongoing, and frequently escalating, perceptions of injustice (Twale, 2018). Faculty self-governance processes that include the nomination and election of a Chair from within a department create situations in which department leaders possess limited management experience or training and instead have spent their careers in competitive isolation as they confront the challenges of publication, teaching, service, tenure and promotion (Taylor, 2013). As a result, Chairs may not have the skills or motivation to effectively intervene to stop abusive conduct among faculty. In addition, in many universities, Chairs do not have actual organizational power when making decisions and so when conflicts arise, Chairs must rely on their Dean to enforce an administrative action. This organizational arrangement creates situations in which Chairs can become targets of their own faculty who may refuse to cooperate in good faith, or who undermine them through the Dean's authority. Alternatively, a Chair who is themselves a bully can use the lack of accountability that accompanies self-governance processes to carry out abusive conduct in relative isolation (Keashly \& Neuman, 2013; Twale, 2018).

In addition to management structures that are easily corrupted, the retention, tenure and promotion process in university workplaces leads to organizational incentives for untenured faculty or those seeking promotion to remain silent in the presence of abusive conduct, either toward themselves or others. Professors working toward tenure or promotion depend on positive recommendations from their department peers, their Chair, their Dean, college-level and university-level committees, as well as the University Provost and President. Each of these recommendations are typically made in unmonitored and confidential meetings and through the use of often subjective, ambiguous or vague performance evaluation policies. Processes to ensure compliance with existing policies, or mechanisms to promote ethical, unbiased and thorough performance evaluations are not a typical aspect of university institutional structures (Twale \& De Luca, 2008). It is easy to see the many ways such a structure can be manipulated to arrive at, and then justify a negative recommendation. As a result, the processes surrounding these decisions, as well as the decisions themselves become mechanisms through which abusive conduct is perpetrated (Keashly \& Neuman, 2010).

For example, Bodensteiner's (2017) qualitative study of targeted faculty reported that faculty with previously strong performance reviews found their evaluations suddenly negative, seemingly without warning. Participants describe receiving reviews in which objective accomplishments were ignored, while narrow and minor issues (such as student evaluations from one course), were overemphasized in order to justify a negative performance evaluation decision (Bodensteiner, 2017). Wilkin (2010) found similar manipulations of the tenure process: targeted faculty described having guidelines for publication changed during the process to exclude their scholarly achievements from review. Similarly, Persky (2018) reports that the threat of negative tenure and promotion decisions was a persistent fear among targeted faculty.

\section{Organizational Culture}

The organizational culture of higher education workplaces produces norms of behavior and shared values that perpetuate bullying and mobbing (Lester, 2009; Twale, 2018). These behavioral expectations are created and perpetuated through the types of rewards and punishments distributed by the organization. Targeted faculty describe a culture of fear, driven by direct and indirect threats of retaliation, which give rise to widespread reluctance to acknowledge the presence of any abusive conduct (Persky, 2018). Lester's (2009) qualitative interviews with community college faculty suggest that faculty were aware of unfair treatment, but understood that the organizational culture would reward their silence and punish their acknowledgement of the abuse. Remaining silent about bullying and mobbing behaviors was viewed as an important way to protect themselves from retaliation, such as altering faculty teaching schedules without need or writing a negative performance review. These fears and resulting lack of participation then allowed only a few people to control organizational processes, which just further perpetuated the bullying (Lester, 2009). Persky's (2018) qualitative study with targeted faculty mirror these findings: there was widespread awareness that upper leadership was abusive, but faculty described an unwillingness to speak out against the behaviors, or use formal processes to grieve them due to fears of direct and indirect retaliation. 
The few faculty members who persist in their efforts to file formal grievances are typically met with additional denials or further abusive conduct. For example, Wilken (2010) reports results from qualitative interviews in which the persistent attempts by faculty to offer objective evidence of overt abuses of power to the provost, diversity officer or human resources leadership were repeatedly ignored. Despite a belief that the bullying behavior would stop as a result of their efforts to document and communicate the abuse, administrators downplayed it and took no action. Descriptions from Keashly and Neuman's (2008) study provide additional examples of a toxic organizational culture. Formal complaints were rarely addressed in the ten-day time frame specified in university policy, and when complaints were addressed, respondents reported that policies were ignored or applied inconsistently. In addition, Bodensteiner (2017) describes findings in which formal attempts to report bullies to human resources were not pursued by the administration because the target was blamed for the problem. Targeted faculty were told they were overreacting or were too emotional and needed to behave like an adult.

These administrative responses are characteristic of a toxic organizational culture in which targets of abusive conduct are manipulated by perpetrators who use a series of communication tactics described as: Deny Attack Reverse Victim and Offender (DARVO) (Harsey et al., 2017). DARVO is used when a target directly confronts a bully about their behavior and the perpetrator then denies the reality of the abuse. The bully then uses verbal abuse to attack the target and they justify this behavior by declaring themselves as the true victim of abuse. DARVO involves the use of stonewalling, which occurs when the perpetrator will not acknowledge a problem by refusing to engage in a discussion about it (Duffy \& Sperry, 2014). Scapegoating is a related strategy in which the target is blamed for the perpetrator's own problems, presumably to protect a fragile self-esteem (Duffy \& Sperry, 2014). Perpetrators who use DARVO also frequently engage in gaslighting: a manipulation tactic in which objective reality is denied by a bully in favor of a false reality in which the bully believes themselves to be the victim who is facing mistreatment (Simon, 1996). Targeted faculty learn that reporting the bullying and mobbing either has no effect on the bullying, or it increases the abusive conduct (Bodensteiner, 2017; Lewis, 2004; Wilken, 2010). As a result, faculty who acknowledge bullying may be quickly met with an organizational culture that leaves them feeling unheard and helpless. The added experience of asking for help and being met with additional abuse in the form of stonewalling, scapegoating and gaslighting compounds the target's trauma and results in an organizational culture that remains silent on the issue of abusive conduct in the workplace.

The types of organizational cultures in which abusive conduct is pervasive are indicative of the "toxic triangle" of destructive leadership (Padilla, 2007). Pelletier et al. (2019) applied this model to a higher education workplace to shed light on the harmful and abusive interactions that developed between a new university president and faculty. The toxic triangle includes leaders at the top who are attention-seeking, narcissistic, self-serving and perpetuate false dichotomies based on who is with them and who is against them (Pelletier, 2010). Toxic leaders are actively supported by individuals who collude with them, either because they share their values, or because they view alignment with the leader as the best way to capitalize on the situation for professional and personal gain. Another part of the toxic triangle includes those who do not actively support the destructive leader, but do conform to the organizational culture for various reasons, such as: 1) a belief that employees should comply with authority; 2) a fear of retaliation if they challenge the leader; 3) an emotional need to be liked by the leader; or 4) a sense of hopelessness about the situation. The final components of the toxic triangle are aspects of the work environment that make it particularly susceptible to destructive leadership, including harmful social norms, instability in the organization, fears of retribution, and a lack of accountability (Pelletier et al., 2019).

Pelletier et al. (2019) observed bullying and mobbing to be present in all aspects of the toxic triangle of destructive leadership. Destructive leaders are themselves abusive and are one source of bullying in the organization. Susceptible followers perpetuate this abuse through their support of the leader and their willingness to engage in bullying behaviors, or remain silent in the presence of mistreatment of others. In Pelletier et al.'s (2019) case study these dynamics were observed to create feedback loops of escalating abusive conduct combined with a lack of resistance to these behaviors. In particular, they characterized the widespread and rigid unwillingness to acknowledge abusive conduct in this organization as a type of "paralysis," and suggested connections with the concept of organizational "miasma," which Gabriel (2012) 
describes as a pervasive learned helplessness among members of an organization. This sense of hopelessness is thought to stem from past traumatic, and unresolved, experiences, often involving the loss of one of more employees from the organization who were terminated under unfair or sudden circumstances, followed by the refusal of the leader to provide a mechanism to say goodbye or symbolically mourn this loss (Gabriel, 2012). In such a situation, harmful norms of behavior can develop which are characterized by self-criticism, suspicion, mistrust, a lack of interest in the organization, and feelings of moral disgust or uncleanliness (Gabriel, 2012). Bullying and mobbing thrive in such an environment.

\section{RESPONSES}

Targeted individuals respond in a variety of ways to workplace bullying and mobbing. Lewis (2004) found feelings of disbelief and shame to be common among targeted faculty. These responses led to difficulties in admitting to themselves and others that they were the target of abusive conduct. These feelings of humiliation and self-blame prevented them from reporting the behaviors in official complaints and led to avoidance and disengagement from work. Similarly, Hollis (2016) reported that targeted faculty spent an average of 3.9 hours a week trying to avoid the bully and $15 \%$ were looking for other employment. Using a different sample, Hollis (2017c) found that $28 \%$ of targeted faculty had tried to leave by applying for another job; $44 \%$ had thought about leaving and 32\% were considering leaving the higher education field. Keashly and Neuman (2008) found a variety of target responses worsened the abusive conduct, including: telling supervisor/chair/dean; ignoring it; asking the bully to stop; behaving extra nice; going along with the behavior; lowering productivity; telling the union; telling the HR department; asking someone to speak to the bully; making a formal complaint; and threatening to tell others. Some responses improved the target's situation including: talking with coworkers; talking with family and friends; staying calm; avoiding the bully; acting as if they didn't care; asking colleagues for help; not taking the behavior seriously; and asking for a transfer.

In addition to the target's own responses, Hollis (2016) asked targets how the organization responded to the bully. Responses included: The organization did nothing (28\%), organization supported the bully (19\%); bully was transferred to another department (19\%); bully was coached (18\%); target was fired (5\%); and bully was fired (4\%). McKay et al. (2008) found that $49 \%$ of targeted respondents did not report the bullying behaviors to administration because they did not believe it would improve their situation; $29 \%$ said they would not report it because it would result in negative consequences for them; $27 \%$ responded yes that they had reported the bullying and $18 \%$ said no because they felt unsafe doing so. Other responses to the bullying included talking with the union (31\%); a lawyer (15\%); equity services $(13 \%)$; an authority figure $(11 \%)$ and $\mathrm{HR}(4 \%)$.

\section{EFFECTS}

Workplace bullying and mobbing are detrimental to the health and well-being of the target, as well as the organization. Research suggests that targets experience myriad harmful effects, most of which are associated with Post Traumatic Stress Disorder (PTSD), which results from exposure to an event or series of events that are perceived as life-threatening and terrifying. While direct threats of violence may be uncommon in university settings, workplace abusive conduct in higher education settings elicits the central fear of losing one's career through having tenure denied, or through a slower process that involves having needed resources withheld; being assigned an unfavorable workload or teaching schedule; or being denied access to advancement opportunities. Accompanying feelings of confusion, shame, fear, desperation and hypervigilance are common components of trauma which manifest in symptoms such as anxiety, depression, sleep disturbances, irritability, difficulties concentrating, and physical manifestations such as muscle aches and pains, headaches, or stomach problems (Hollis, 2019c; Matthiessen, \& Einarsen, 2004; McKay et al., 2008; Taspinar et al., 2013). McKay et al.'s (2008) survey of targeted faculty reported the following most common effects of workplace bullying: stress $(55 \%)$, frustration $(49 \%)$, anger (47\%), demoralization (39\%), powerlessness $(37 \%)$ anxiety $(35 \%)$, exhaustion $(33 \%)$ and irritability $(28 \%)$. Hollis 
(2019c) reports survey results from targeted faculty that document the negative health effects of bullying, including: trouble sleeping (74\%); increased alcohol use (36\%); the use of professional counseling support (33\%); taking sleep medication (24\%); taking prescription medication (20\%); and experiencing suicidal ideation (9\%). Similarly, Burris (2012) found that targeted faculty felt devalued, humiliated, and emotionally unsafe.

In addition to these negative health outcomes, frustration with work activities and disengagement from the workplace are also common effects of workplace abusive conduct. Meriläinen et al. (2016) reported five primary ways that bullying affected the work of the targets in their survey: 1) exclusion and discrimination, reflected in descriptions of a lack of cooperation and collaboration, and a lack of clarity in work assignments; 2) feelings of anxiety, uncertainty or helplessness, reflected in descriptions of emotional turmoil, hypervigilance; and concentration problems; 3) decreasing professional self-confidence, motivation and work-related well-being, reflected in descriptions of questioning one's competence, a desire to change work places or professions, and an avoidance of new responsibilities; 4) decreasing work performance; reflected in descriptions of inability to focus on one's scholarly work, avoiding meetings, and ruminations about how to avoid the bully; and 5) worsening of working environment, reflected in descriptions of a strong desire to avoid work and work-related activities and environments. Other effects on the target include low job satisfaction and decreased productivity (McKay et al., 2008).

Similarly, Meriläinen, Köiv et al. (2019) conducted multivariate analyses using survey data from faculty in Estonia and found associations between workplace bullying, decreased work performance and reduced engagement in work activities. Reduced productivity, decreased motivation and avoidance of work are costly to the organization. Hollis (2015) estimated the fiscal cost of workplace bullying by using survey responses from targeted faculty who reported the amount of lost work time that resulted from the bullying. This information was combined with an hourly salary rate to estimate overall financial loss to the organization. Annual costs for a medium private university were reported as: $\$ 4,684,999$; a large state university: $\$ 93,699,980$; and a small liberal arts college: $\$ 8,092,271$.

\section{AREAS FOR FUTURE RESEARCH}

This review of the literature provides an overview of the current state of empirical and theoretical knowledge on bullying and mobbing in higher education workplaces and points to areas of future research. First, research that moves beyond documenting prevalence to illuminating the ways that workplace bullying and mobbing are harming the role of universities in society is needed. In particular, abusive conduct in an educational setting threatens the ability of faculty to exercise their academic freedom rights and responsibilities. Academic freedom is defined as professional autonomy in the areas of: 1) scholarly/research interests and activities; 2) course content and student grading; 3) expression of opinions related to faculty governance of the university (American Association of University Professors, n. d.). Universities are founded on the notion of freedom of thought and dialogue; facilitation of critical thinking skills; and faculty ownership of university governance. Workplace bullying corrodes academic freedom by perpetuating a culture of fear in which faculty rightfully perceive the threat of retaliation if they share dissenting views; choose curriculum that others may not like; or research unpopular questions (Hollis, 2018b). Pelletier et al.'s (2019) case study revealed that these chilling effects extended beyond meeting rooms and into classrooms: as abusive conduct at the university became more prevalent, student retention rates dropped and faculty to student ratios increased. More research on the effects of workplace bullying in higher education on teaching and student domains, as well as research and faculty governance is needed.

Such research will help demonstrate the connections between the behaviors of faculty and the erosion of academic freedom. Demonstrating these connections has the potential to shed light on the mechanisms through which workplace bullying in universities reduces the quality of education; stifles open dialogue on governance issues; and encourages conformity in research and scholarly activities.

Hollis (2018b) suggests the use of guidelines on collegial or civil communications in higher education settings is sometimes misinterpreted as an infringement on the free speech rights of faculty. There is a concern that policies about how faculty speak to one another and to their students could be manipulated to 
stifle free and open discourse, dialogue and debate. While the potential for unintended consequences to workplace bullying policies is real and should be monitored, the harm that is being caused by the widespread prevalence of workplace abusive conduct in higher education must be addressed. Given that bullying behaviors frequently produce a chilling effect on the willingness of faculty to participate fully in their professional role, stopping unethical, intimidating and harassing communication and behaviors actually serves to encourage the diversity of thought and expression that are needed to develop new ideas and produce knowledge (Hollis, 2018b). Introducing anti-bullying policies may be an important first step to stop these behaviors. The U.S. has no national workplace bullying policy, however countries such as Australia, Canada, and Sweden have passed workplace bullying legislation (WBI, 2021). Research on policies that are specific to higher education workplaces is needed, including the proportion of universities with a workplace bullying policy; the benefits and challenges associated with these policies and their effects on abusive conduct among university faculty. Although Title IX and civil rights laws in the U.S. are intended to prohibit discrimination based on sex, race, and other identity characteristics, the application of these policies in legal cases in university settings is often unsuccessful (Stone, 2013). Research on organization-specific policies is needed to move our knowledge of this topic forward toward solutions.

Similarly, more research is needed on how to change the institutional structures and organizational cultures within universities that promote and allow abusive conduct. Although policies are critical, they need to be accompanied by changes in current reward systems that incentivize bullying and institutional structures that are easily corrupted (Twale \& De Luca, 2008). Research on higher education workplaces that is actively addressing these issues is needed so that evidence on best practices to reduce and eliminate bullying in higher education workplaces can be established and disseminated. For example, Roderick (2016) reported efforts at the University of Alaska Anchorage to promote a collegial workplace. Recommendations related to changing an abusive organizational culture included: using short, online educational modules for all employees to increase awareness about workplace bullying; specific training for chairs and deans on how to promote non-abusive communication between faculty; and adding language to union contracts and hiring descriptions related to workplace bullying. These strategies have the potential to increase knowledge in an organization about workplace bullying and the expectations of the university with respect to employee behaviors; however more research is needed on the empirical outcomes of such efforts, as well as other potentially effective actions. Research on practices that are successful in changing organizational incentives away from abusive conduct and toward a culture that rewards fairness, decency, dignity, and kindness is critical.

\section{REFERENCES}

American Association of University Professors. (n.d.). 1940s Statement of Principles on Academic Freedom and Tenure. Retrieved from https://www.aaup.org/report/1940-statement-principlesacademic-freedom-and-tenure

Anjum, A., \& Muazzam, A. (2018). The gendered nature of workplace bullying in the context of higher education. Pakistan Journal of Higher Education Research, 33(2), 493-505.

American Psychiatric Association. (2013). Diagnostic and statistical manual of mental disorders (5th ed.). Washington, DC: Publisher.

Berryman-Fink, C. (1998). Can We Agree to Disagree? Faculty-Faculty Conflict. In S.A. Holton (Ed.), Mending the Cracks in the Ivory Tower: Strategies for Conflict Management in Higher Education (pp. 141-163). Bolton, MA: Anker Publishing Company, Inc.

Bergen Bullying Research Group. (2020). Negative Acts Questionnaire. Retrieved from https://www.uib.no/en/rg/bbrg/44045/naq

Bodensteiner, A. (2017). A Phenomenological Study of Bullying Experienced by Graduate Students and Faculty Through the Lens of Power. University of North Dakota. Theses and Dissertations, 2172. Retrieved from https://commons.und.edu/theses/2172

Brodsky, C. (1976). The harassed worker. Lexington MA: Lexington Books. 
Buitenhuis, E.B. (2016). Politics, Pedagogy and Power: Bullying in Faculties of Education. New York: Peter Lang.

Burris, P. (2012). A phenomenological investigation of experiences regarding workplace bullying in higher education (Publication No. 3524439) [Doctoral Dissertation, University of South Dakota]. ProQuest Dissertations Publishing.

Cassidy, W., Faucher, C., \& Jackson, M. (2014). The dark side of the ivory tower: Cyberbullying of university faculty and teaching personnel. Alberta Journal of Educational Research, 60(2), 279299.

Davenport, N., Schwartz, R.D., \& Elliot, G.P. (1999). Mobbing: Emotional abuse in the American workplace. Ames Iowa: Civil Society Publishing.

Duffy, M., \& Sperry, L. (2012). Mobbing: Causes, Consequences, and solutions. New York: Oxford University Press.

Duffy, M., \& Sperry, L. (2014). Overcoming Mobbing: A recovery guide for workplace aggression and bullying. New York: Oxford University Press.

Einarsen, S., Hoel, H., Zapf, D., \& Cooper, C.L. (2003). The concept of bullying at work: The European tradition. In S. Einarsen, H. Hoel, D. Zapf, \& C.L. Cooper (Eds.), Bullying and Emotional Abuse in the Workplace: International Perspectives in Research and Practice. London: Taylor \& Francis.

Einarsen, S., Aasland, M.S., \& Skogstad, A. (2016). The nature and outcomes of destructive leadership behavior in organizations. In R.J. Burke \& C.L. Cooper (Eds.), Risky business: Psychological, Physical and Financial Costs of High-Risk Behavior in Organizations (pp. 323-349). New York, NY: Routledge.

Einarsen, S., Hoel, H., \& Notelaers, G. (2009). Measuring exposure to bullying and harassment at work: Validity, factor structure and psychometric properties of the Negative Acts QuestionnaireRevised. Work \& Stress, 23(1), 24-44. doi:10.1080/02678370902815673

Einarsen, S., Hoel, H., Zapf, D., \& Cooper, C.L. (Eds.). (2011). Bullying and harassment in the workplace: Developments in theory, research, and practice (2nd ed.) London: CRC Press.

Einarsen, S., \& Nielsen, M.B. (2015). Workplace bullying as an antecedent of mental health problems: A five-year prospective and representative study. International Archives of Occupational and Environmental Health, 88(2), 131-142.

Einarsen, S., Raknes, B.I., \& Matthiesen, S.B. (1994). Bullying and harassment at work and their relationships to work environment quality: An exploratory study. European Journal of Work and Organizational Psychology, 4(4), 381-401. https://doi.org/10.1080/13594329408410497

Erdemir, B., Demir, C., Öcal, J., \& Kondakç1, Y. (2020). Academic mobbing in relation to leadership practices: A new perspective on an old issue. The Educational Forum, 84(2), 126-139.

Gabriel, Y. (2012). Organizations in a state of darkness: Toward a theory of organizational miasma. Organization Studies, 33(9), 1137-1152.

Goode, W.J. (1967). The protection of the inept. American Sociological Review, 32(1), 5-19. https://doi.org/10.2307/2091714

Harsey, S.J., Zurbriggen, E.L., \& Freyd, J.J. (2017). Perpetrator responses to victim confrontation: DARVO and victim self-blame. Journal of Aggression, Maltreatment and Trauma, 26(6), 644 663. doi: 10.1080/10926771.2017.1320777

Heinemann, P-P. (1972). Gruppvåld bland barn och vuxna [Group violence among children and adults]. Stockholm: Natur och kultur.

Hermanowicz, J.C. (2013). The culture of mediocrity. Minerva, 51, 363-387. https://doi.org/10.1007/s11024-013-9231-0

Hollis, L.P. (2015). Bully university? The cost of workplace bullying and employee disengagement in American higher education. SAGE Open, 5(2), 1-11. doi:10.1177/2158244015589997

Hollis, L.P. (2016). Bruising the bottom line: Cost of workplace bullying and the compromised access for underrepresented community college employees. In L.P. Hollis (Ed.), The coercive community 
college: Bullying and its costly impact on the mission to serve underrepresented populations (Diversity in Higher Education, Vol. 18) (pp. 113-123). Emerald Group Publishing Limited.

Hollis, L.P. (2017a). Workplace bullying in the United States and Canada: Organizational accountability required in higher education. Comparative Civilization Review, 76(27), 117-132. Retrieved from https://scholarsarchive.byu.edu/ccr/vol76/iss76/13

Hollis, L.P. (2017b). Higher education henchman: Vicarious bullying and underrepresented populations. Advances in Social Sciences Research Journal, 4(12), 64-73. http://dx.doi.org/10.14738/assrj.412.3364

Hollis, L.P. (2017c). This is why they leave you: Workplace bullying and insight to junior faculty departure. British Journal of Education, 5(10), 1-7. Retrieved from http://www.eajournals.org/wp-content/uploads/This-Is-Why-They-Leave-You-WorkplaceBullying-and-Insight-to-Junior-Faculty-Departure.pdf

Hollis, L.P. (2018a). Bullied Out of Position: Black Women's Complex Intersectionality, Workplace Bullying, and Resulting Career Disruption. Journal of Black Sexuality and Relationships, 4(3), 73-89. https://doi.org/10.1353/bsr.2018.0004

Hollis, L.P. (2018b). The ironic interplay of free speech and silencing: Does workplace bullying compromise free speech in higher education. AAUP Journal of Academic Freedom, 9, 1-15. Retrieved from https://files.eric.ed.gov/fulltext/ED590660.pdf

Hollis, L.P. (2019a). The abetting bully: Vicarious bullying and unethical leadership in higher education. Journal for the Study of Postsecondary and Tertiary Education, 4, 1-18. https://doi.org/10.28945/4255

Hollis, L.P. (2019b). Something to lose sleep over? Predictive analysis of black men's and white men's insomnia issues due to workplace bullying in higher education. Journal of Black Sexuality and Relationships, 5(4), 1-19. doi:10.1353/bsr.2019.0007

Hollis, L.P. (2019c). Analysis of faculty wellness and workplace bullying. American Educational Research Association, Ontario Canada. Washington DC: American Educational Research Association. Retrieved from https://files.eric.ed.gov/fulltext/ED593910.pdf

Hollis, L.P., \& Robinson, S. (2016). Insult to injury: The extent of bullying for gender and sexual minorities in community colleges. In L.P. Hollis (Ed.), The coercive community college: Bullying and its costly impact on the mission to serve underrepresented populations (Diversity in Higher Education, Vol. 18) (pp. 113-123). Emerald Group Publishing Limited. https://doi.org/10.1108/S1479-364420160000018013

Keashly, L., \& Neuman, J.H. (2008). Final report: Workplace behavior (bullying) project survey. Mankato, MN: Minnesota State University. Online. Retrieved from https://www.mnsu.edu/csw/workplacebullying/workplace_bullying_final_report.pdf

Keashly, L., \& Neuman, J.H. (2010). Faculty experiences with bullying in higher education: Causes, consequences, and management. Administrative Theory \& Praxis, 32(1), 48-70. doi 10.2753/ATP1084-1806320103

Keashly, L., \& Neuman, J.H. (2013). Bullying in academia: What does current theorizing and research tell us? In J. Lester (Ed.), Workplace bullying in higher education (pp. 1-22). New York, NY: Routledge.

Klein, C., \& Lester, J. (2013). Moving beyond awareness and tolerance: Recommendations and implications for workplace bullying in higher education. In J. Lester (Ed.), Workplace bullying in higher education (pp. 138-147). New York, NY: Routledge.

Lester. J. (2009). Not your child's playground: Workplace bullying among community college faculty. Community College Journal of Research and Practice, 33(5), 444-462. doi: $10.1080 / 10668920902728394$

Lewis, D. (2004). Bullying at work: the impact of shame among university and college lecturers. British Journal of Guidance and Counseling, 32(3), 281-299. doi: 10.1080/03069880410001723521

Leymann, H. (1990). Mobbing and psychological terror at workplaces. Violence and Victims, 5, 119-126.

Lorenz, K. (1966). On aggression. New York: Harvest. 
Matthiessen, S., \& Einarsen, S. (2004). Psychiatric distress and symptoms of PTSD among victims of bullying at work. British Journal of Guidance \& Counseling, 32(3), 335-356. doi: $10.1080 / 03069880410001723558$

McKay, R., Arnold, D.H., Fratzl, J., \& Thomas, R. (2008). Workplace bullying in academia: A Canadian study. Employee Responsibilities and Rights Journal, 20, 77-100. doi: 10.1007/s10672-0089073-3

Meriläinen, M., Sinkkonen, H-M., Puhakka, H., \& Käyhkö, K. (2016). Bullying and inappropriate behavior among faculty personnel. Policy Futures in Education, 14(6), 617-634. doi: $10.1177 / 1478210316639417$

Meriläinen, M., Käyhkö, K., Köiv, K. \& Sinkkonen, H. (2019). Academic bullying among faculty personnel in Estonia and Finland. Journal of Higher Education Policy and Management, 41(3), 241-261. https://doi.org/10.1080/1360080X.2019.1591678

Meriläinen, M., Köiv, K., \& Honkanen, A. (2019). Bullying effects on performance and engagement among academics. Employee Relations: The International Journal, 41(6), 1205-1223. doi 10.1108/ER-11-2017-0264

Mourssi-Alfash, M. (2014). Workplace bullying and its influence on the perception of organizational justice and organizational citizenship behavior in higher education. (Publication No. 3615122) [Doctoral dissertation, Capella University]. ProQuest Dissertations Publishing.

Namie, G. (2021). 2021 Workplace Bullying Institute U.S. Workplace Bullying Survey. Retrieved from https://workplacebullying.org/wp-content/uploads/2021/03/2021-Full-Report.pdf

Padilla, A., Hogan, R., \& Kaiser, R.B. (2007). The toxic triangle: Destructive leaders, susceptible followers and conducive environments. The Leadership Quarterly, 18, 176-194.

Pelletier, K. (2010). Leader toxicity: An empirical investigation of toxic behavior and rhetoric. Leadership, 6(4), 373-389.

Pelletier, K., Kottke, J.L., \& Sirotnik, B.W. (2019). The toxic triangle: A case analysis of the emergence and manifestation of toxicity in a public university. Leadership Quarterly, 15(4), 405-432.

Persky, L. (2018). The perceived effects of organizational culture on workplace bullying in higher education. (Paper No. 357) [Doctoral dissertation, St. John Fisher College]. Retrieved from https://fisherpub.sjfc.edu/education_etd/357/

Piotrowski, C., \& King, C. (2016). The enigma of adult bullying in higher education: A research-based conceptual framework. Education, 136(3), 299-306.

Roderick, L. (2016). Toxic Friday: Resources for addressing faculty bullying in higher education. Anchorage AK: University of Alaska Anchorage.

Ross, D.B., Sasso, M.T., Matheson, CE., \& Matheson, R.W. (2019). Narcissistic and sociopathic leadership and the world of higher education: A place for mentoring, not mobbing. In C.M. Crawford (Ed.), Confronting academic mobbing in higher education (pp. 69-103). Hershey PA: IGI Global.

Simon, G. (1996). In sheep's clothing: Understanding and dealing with manipulative people. Marion, MI: Parkhurst Brothers.

Stone, K. (2013). Workplace bullying in higher education: Some legal background. In J. Lester (Ed), Workplace bullying in higher education (pp. 87-103). New York, NY: Routledge.

Taspinar, B., Taspinar, F., Guclu, S., Nalbant, A., Calik, B.B., Uslu, A., \& Inal, S. (2013). Investigation of the association between mobbing and musculoskeletal discomfort and academicians. Japanese Psychological Research, 55(4), 400-408.

Taylor, S.K. (2012). Workplace bullying in higher education: Faculty experiences and responses. (Publication No.3505900) [Doctoral dissertation, University of Minnesota] ProQuest Dissertation $\&$ Theses Global.

Taylor, S.K. (2013). Workplace bullying: Does tenure change anything? In J. Lester (Ed.), Workplace bullying in higher education (pp. 23-40). New York, NY: Routledge. 
Tran, B.N. (2019). Workplace bullying and job satisfaction in higher education: A causal-comparative study. (Publication No.13428329) [Doctoral dissertation, St. Thomas University] ProQuest Dissertation \& Theses Global.

Twale, D.J. (2018). Understanding and preventing faculty-on-faculty bullying: A Psycho-socialorganizational approach. New York: Taylor \& Francis.

Twale, D.J., \& De Luca, B.M. (2008). Faculty incivility: The rise of the academic bully culture and what to do about it. San Francisco: Jossey-Bass.

Westhues, K. (1998). Eliminating professors: A guide to the dismissal process. Queenstown, Ontario: Kempner Collegium Publications.

Westhues, K. (2005). The envy of excellence: Administrative mobbing of high-achieving professors. Lewiston, NY: The Tribunal for Academic Excellence/Edwin Mellon Press.

Westhues, K. (2006). The unkindly art of mobbing, Academic Matters, (Fall), 18-20.

Wilkin, L. (2010). Workplace bullying in academe: A grounded theory study exploring how faculty cope with the experience of being bullied. (Publication No. 3447190) [Doctoral dissertation, Nova Southeastern University] ProQuest Dissertation \& Theses Global.

Workplace Bullying Institute. (2021). WBI Healthy Workplace Bill. Retrieved from https://workplacebullying.org/hwb/

Yildirim, D., Yildirim, A., \& Timucin, A. (2007). Mobbing behaviors encountered by nurse teaching staff. Nursing Ethics, 14(4), 447-463. doi:10.1177/0969733007077879 